\title{
Hubungan Health Locus of Control dengan Kepatuhan Diet pada Pasien Diabetes Mellitus Tipe 2 di RSUD Kota Depok Tahun 2020
}

\section{Relationship between Health Locus of Control with Dietary Adherence Among Patient with Type 2 Diabetes Mellitus at Depok City Hospital in 2020}

\author{
Shania Adhanty ${ }^{1 *}$, Dian Ayubi $^{1}$, Dien Anshari ${ }^{1}$ \\ ${ }^{1}$ Departemen Pendidikan Kesehatan dan Ilmu Perilaku, Fakultas Kesehatan Masyarakat, Universitas \\ Indonesia, Depok 16424 \\ *Korespondensi penulis: \\ shaniadha16@gmail.com

$\begin{array}{ll}\text { Diterima (Recieved) } & : 19 \text { Agustus } 2020 \\ \text { Direvisi (Revised) } & : 17 \text { November } 2020 \\ \text { Diterima untuk diterbitkan (Accepted) } & : 5 \text { Februari } 2021\end{array}$

\section{ABSTRAK}

Latar Belakang. Diabetes Mellitus (DM) telah menyebabkan 4,2 juta kematian pada tahun 2019. Di Indonesia, penyakit DM merupakan salah satu PTM yang menyebabkan kematian utama. Kepatuhan diet menjadi perilaku yang sangat penting dan diperlukan kendali diri.

Tujuan. Tujuan penelitian adalah mengetahui hubungan lokus kendali diri untuk sehat baik dimensi internal, orang berpengaruh, keberuntungan dan faktor lainnya dengan kepatuhan diet pasien DM tipe 2 di RSUD Kota Depok tahun 2020.

Metode. Penelitian menggunakan desain cross-sectional, pengambilan data dilakukan melalui convenience sampling pada 52 pasien DM tipe 2 yang berkunjung ke poli penyakit dalam RSUD Kota Depok.

Hasil. Pasien memiliki nilai kepatuhan diet yang cukup yaitu 66,23 dari skala 100. Hasil uji korelasi pearson menunjukkan terdapat hubungan yang signifikan dengan kekuatan sedang dan positif antara lokus kendali untuk sehat dimensi internal dan dimensi orang berpengaruh dengan kepatuhan diet $(r=0,46$ dan $r=0,28)$ diikuti dengan dimensi keberuntungan menunjukkan kekuatan sedang dan negatif terhadap kepatuhan diet $(\mathrm{r}=$ $-0,28)$.

Kesimpulan. Terdapat hubungan yang signifikan antara health locus of control dimensi internal, powerful others dan chance dengan kepatuhan diet dengan kekuatan hubungan sedang dan arah korelasi positif pada dimensi internal dan powerful others sedangkan negatif pada dimensi chance.

Kata Kunci: diabetes mellitus, penatalaksanaan DM, kepatuhan diet, lokus kendali diri untuk sehat

\begin{abstract}
Background. Diabetes Mellitus (DM) caused 4.2 million deaths in 2019. In Indonesia, DM is an NCD that causes major deaths. Dietary adherence becomes a vital behavior and requires self-control.

Objective. This study aimed to determine the relationship between health locus of control on internal, powerful-others, chance dimensions and other factors with dietary adherence among type 2 DM patients at Depok City Hospital in 2020.

Method. This study used a cross-sectional design and data collection through convenience sampling on 52 type 2 DM patients who visited internist poly in Depok City Hospital.

Results. This study indicates that patients have adequate dietary adherence values 66,23 on a scale of 100 . Pearson correlation test results show a significant relationship between health locus of control on internal and powerful-others dimensions with a moderate and positive relationship with dietary adherence $(r=0,46$ and $r=0,28)$. Meanwhile, the chance dimension shows a moderate and negative relationship with dietary adherence $(r=-0,28)$.

Conclusion: There is a significant relationship between health locus of control internal, powerful others and chance dimensions with dietary compliance with moderate strength. The direction of the correlation is positive on the internal dimension and powerful others while negative on the chance dimension.
\end{abstract}

Keywords: diabetes mellitus; diabetes self-care behaviour; dietary adherence; health locus of control 


\section{LATAR BELAKANG}

Menurut WHO, penyakit tidak menular (PTM) telah menyumbang $71 \%$ kematian di dunia per tahunnya. Lebih dari $80 \%$ kematian akibat PTM disebabkan oleh penyakit kardiovaskuler, kanker, diabetes mellitus (DM) dan diikuti dengan kematian akibat penyakit pernapasan. ${ }^{1}$ Menurut International Diabetes Federation $(2020)^{2}$, terdapat sekitar 463 juta orang dewasa berusia 20-79 tahun menderita DM dan telah menyebabkan 4,2 juta kematian pada tahun 2019. Hasil Riskesdas pada tahun 2013 menunjukkan bahwa proporsi penderita DM terbesar berada di Provinsi Jawa Barat. $^{3}$ Berdasarkan Profil Kesehatan Depok tahun $2018^{4}, 10$ penyebab kematian utama pasien yang berobat di rumah sakit (RS) salah satunya diakibatkan oleh penyakit DM $(3,11 \%)$. Permasalahan penyakit DM tipe 2 yang tidak ditangani akan menimbulkan berbagai komplikasi penyakit yang dapat menyebabkan peningkatan jumlah kematian. Oleh karena itu, kepatuhan dalam melakukan tatalaksana DM diperlukan, salah satunya adalah kepatuhan diet.

Kepatuhan merupakan derajat dimana seseorang melakukan perilaku yang berkaitan dengan kesehatan, baik meminum obat, mengikuti terapi diet dan mengubah gaya hidup sesuai rekomendasi yang diberikan oleh tenaga kesehatan ${ }^{5}$. Kepatuhan terhadap rekomendasi diet yang disarankan oleh tenaga kesehatan tentunya akan menimbulkan dampak positif. Selain mengurangi beban penyakit, kepatuhan yang dilaksanakan juga dapat mengurangi morbiditas dan mortalitas dari komplikasi ${ }^{6}$. Kepatuhan diet dapat dipengaruhi oleh berbagai faktor yaitu faktor predisposisi seperti karakteristik individu dan psikososial, faktor penguat seperti dukungan keluarga atau tenaga kesehatan dan faktor pemungkin seperti pemberian pelayanan dan jarak ke fasilitas kesehatan.

Faktor psikososial yang diterapkan dalam bidang kesehatan diukur dengan Health Locus of Control atau lokus kendali untuk sehat. ${ }^{7,8}$ Health locus of control (HLOC) memiliki tiga dimensi, diantaranya adalah internal health locus of control atau lokus kendali untuk sehat internal, merupakan suatu keyakinan dimana kondisi kesehatan seseorang dipengaruhi oleh perilaku dirinya sendiri. Selanjutnya dimensi powerful others health locus of control atau lokus kendali untuk sehat orang-orang yang berpengaruh merupakan suatu keyakinan dimana kondisi kesehatan seseorang dipengaruhi oleh orang lain yang memiliki pengaruh kuat (dokter atau tenaga kesehatan) maupun orang disekitarnya. Chance locus of control atau lokus kendali keberuntungan merupakan keyakinan dimana kondisi kesehatan dipengaruhi oleh keberuntungan atau takdir yang diberikan kepadanya. ${ }^{7,9}$

Berdasarkan data di RSUD Kota Depok pada tahun 2019, penyakit DM tipe 2 tanpa komplikasi merupakan satu dari 10 besar penyakit yang ditemui di poliklinik dengan jumlah sebanyak 3525 kasus. Selain itu, berdasarkan wawancara dengan dokter spesialis penyakit dalam RSUD Kota Depok, pasien DM cenderung masih kurang patuh terhadap diet. Penelitian ini bertujuan ingin mengetahui hubungan health locus of control dengan kepatuhan diet disertai dengan penelitian terhadap faktor lainnya yang dianggap mempengaruhi kepatuhan diet. Hasil penelitian ini penting untuk menentukan perlakukan yang tepat bagi penderita DM tipe 2.

\section{METODE}

Desain penelitian ini menggunakan crosssectional dengan pendekatan kuantitatif. Penelitian dilakukan di Rumah Sakit Umum Daerah (RSUD) Kota Depok periode Juni sampai Juli tahun 2020. Sampel penelitian ini adalah pasien DM tipe 2 yang datang berkunjung ke poli penyakit dalam dengan kriteria berusia diatas 20 tahun, telah didiagnosis DM tipe 2 oleh dokter minimal setahun, memiliki kemampuan mendengar, menulis dan membaca dengan baik dan bersedia menjadi responden. Teknik pengambilan sampel yang dilakukan adalah non-probability sampling dan jenis penarikan sampel yang digunakan adalah convenience sampling dengan jumlah sampel sebanyak 52 orang. Pengambilan data dilakukan dengan cara pengisian kuesioner mandiri oleh responden yang memenuhi kriteria penelitian. Sebelumnya sudah dilakukan koordinasi terkait pemilihan responden dan pengambilan data dengan dokter dan perawat poli. Pada saat proses pengambilan data, perawat membantu peneliti untuk memberikan informasi pengisian kuesioner 
kepada responden. Instrumen pengambilan data yang digunakan adalah kuesioner kepatuhan diet oleh Susanti ${ }^{10}$, kuesioner multidimensional health locus of control questionnaire form $c$ yang diadaptasi dan diterjemahkan dari Minhas ${ }^{11}$, Hidayati ${ }^{12}$ dan Susanti $^{10}$ untuk mengukur health locus of control responden pada masing-masing dimensi, diabetes knowledge questionnaire yang telah diterjemahkan oleh Gultom ${ }^{13}$ dan kuesioner pengetahuan DM oleh Lestari ${ }^{14}$ untuk mengukur pengetahuan responden terhadap DM secara umum serta kuesioner data diri responden (pendidikan, jenis kelamin, usia, pekerjaan dan lama menderita DM). Analisis data yang dilakukan adalah analisis univariat dan analisis bivariat yang menggunakan uji korelasi pearson dan independent $t$ test.

\section{HASIL}

Tabel 1 menunjukkan distribusi jawaban kepatuhan diet dimana $73.1 \%$ responden kadang-kadang tidak makan tepat waktu jika sibuk, $76.9 \%$ mengkonsumsi makanan yang mengandung lemak dan $65.4 \%$ merasa bahwa jadwal makan yang dianjurkan sulit diikuti.

Tabel 2 memperlihatkan rata-rata nilai kepatuhan diet responden dengan nilai yang didapatkan adalah sebesar 66,23 (skala 100) dengan nilai terendah adalah 37,04 dan yang paling tinggi adalah 88,89 .

Tabel 3 menunjukkan distribusi jawaban health locus of control. Pada butir internal, $67.3 \%$ responden setuju bahwa hal yang dilakukan oleh diri sendiri dapat mempengaruhi kondisi kesehatan. Pada butir powerful-others, $51.9 \%$ responden setuju bahwa dengan menemui dokter secara teratur akan mempengaruhi kondisi kesehatan serta $32.7 \%$ responden setuju bahwa dengan adanya bantuan dari orang lain akan mempengaruhi kondisi kesehatan. Pada butir chance, 30.8\% responden setuju jika kondisi kesehatan memburuk merupakan nasib.

Tabel 1. Distribusi Responden Menurut Butir-Butir Kepatuhan Diet pada Pasien DM Tipe 2 di RSUD Kota Depok Tahun 2020

\begin{tabular}{|c|c|c|c|c|c|c|c|c|}
\hline \multirow{2}{*}{ Butir-Butir Kepatuhan Diet } & \multicolumn{2}{|c|}{$\begin{array}{c}\text { Tidak } \\
\text { Pernah }\end{array}$} & \multicolumn{2}{|c|}{$\begin{array}{l}\text { Kadang- } \\
\text { kadang }\end{array}$} & \multicolumn{2}{|c|}{ Sering } & \multicolumn{2}{|c|}{ Rutin } \\
\hline & $\mathbf{f}$ & $\%$ & $\mathbf{f}$ & $\%$ & f & $\%$ & f & $\%$ \\
\hline \multicolumn{9}{|l|}{ Jadwal Makan } \\
\hline - $\quad$ Makan tepat waktu sesuai jadwal & 2 & 3,8 & 21 & 40,4 & 12 & 23,1 & 17 & 32,7 \\
\hline - $\quad$ Tidak makan tepat waktu jika sibuk & 5 & 9,6 & 38 & 73,1 & 6 & 11,5 & 3 & 5,8 \\
\hline $\begin{array}{l}\text { - Memakan makanan kecil (ngemil) diluar } \\
\text { jadwal makan }\end{array}$ & 6 & 11,5 & 32 & 61,5 & 14 & 26,9 & - & - \\
\hline - $\quad$ Tidak mencatat menu makanan & 31 & 59,6 & 11 & 21,2 & 5 & 9,6 & 5 & 9,6 \\
\hline \multicolumn{9}{|l|}{ Memilih Jenis Makanan } \\
\hline - Manis & 18 & 34,6 & 30 & 57,7 & 4 & 7,7 & - & - \\
\hline - Mengandung lemak & 6 & 11,5 & 40 & 76,9 & 6 & 11,5 & - & - \\
\hline - Mengandung vitamin/mineral & 5 & 9,6 & 15 & 28,8 & 22 & 42,3 & 10 & 19,2 \\
\hline - Mengandung protein & 1 & 1,9 & 24 & 46,2 & 18 & 34,6 & 9 & 17,3 \\
\hline - Sayur dan buah-buahan & 1 & 1,9 & 13 & 25,0 & 17 & 32,7 & 21 & 40,4 \\
\hline$-\quad$ Asin & 15 & 28,8 & 26 & 50,0 & 8 & 15,4 & 3 & 5,8 \\
\hline - Membuat variasi menu makanan & 1 & 1,9 & 20 & 38,5 & 18 & 34.6 & 13 & 25,0 \\
\hline - Menggunakan gula khusus diabetes & 8 & 15,4 & 18 & 34,6 & 10 & 19,2 & 16 & 30,8 \\
\hline \multicolumn{9}{|l|}{ Kepatuhan Terhadap Jumlah Makanan } \\
\hline - Makan lebih dari 3 kali dalam sehari & 22 & 42,3 & 24 & 46,2 & 3 & 5,8 & 3 & 5,8 \\
\hline \multicolumn{9}{|l|}{ Pengaturan Berat Badan (BB) } \\
\hline - $\quad$ Menimbang BB secara teratur & 2 & 3,8 & 25 & 48,1 & 6 & 11,5 & 19 & 36,5 \\
\hline \multicolumn{9}{|c|}{ Kepatuhan Terhadap Rekomendasi Tenaga Kesehatan } \\
\hline - Makan sesuai anjuran dokter & 2 & 3,8 & 23 & 44,2 & 15 & 28,8 & 12 & 23,1 \\
\hline - $\quad$ Tidak mengikuti anjuran diet & 23 & 44,2 & 23 & 44,2 & 4 & 7,7 & 2 & 3,8 \\
\hline - Jadwal makan yang dianjurkan sulit & 13 & 25,0 & 34 & 65,4 & 5 & 9,6 & - & - \\
\hline $\begin{array}{ll}\text { diikuti } \\
\text { _ } & \text { Memeriksa kadar gula darah secara rutin }\end{array}$ & 4 & 7,7 & 4 & 7,7 & 8 & 15,4 & 36 & 69,2 \\
\hline
\end{tabular}


Tabel 2. Deskripsi Nilai Kepatuhan Diet Responden pada Pasien DM Tipe 2 di RSUD Kota Depok Tahun 2020

\begin{tabular}{cc}
\hline Ukuran & Nilai* \\
\hline Mean & 66,23 \\
Minimal & 37.04 \\
Maksimal & 88,89 \\
\hline
\end{tabular}

(*) Ket: Nilai dalam skala 100

Tabel 3. Distribusi Responden Menurut Butir-Butir Health Locus of Control pada Pasien DM Tipe 2 di RSUD Kota Depok Tahun 2020

\begin{tabular}{|c|c|c|c|c|c|c|c|c|c|c|c|c|}
\hline \multirow[t]{2}{*}{ Butir-Butir Health Locus of Control } & \multicolumn{2}{|c|}{ STS } & \multicolumn{2}{|c|}{ TS } & \multicolumn{2}{|c|}{ ATS } & \multicolumn{2}{|c|}{$\mathbf{A S}$} & \multicolumn{2}{|c|}{$\mathbf{S}$} & \multicolumn{2}{|c|}{ SS } \\
\hline & $\mathbf{f}$ & $\%$ & $\mathbf{F}$ & $\%$ & f & $\%$ & f & $\%$ & $\mathbf{f}$ & $\%$ & f & $\%$ \\
\hline Internal health locus of control & & & & & & & & & & & & \\
\hline $\begin{array}{l}\text { - Perilaku yang dilakukan oleh diri } \\
\text { sendiri akan menentukan } \\
\text { kesembuhan }\end{array}$ & 2 & 3,8 & 4 & 7,7 & 1 & 1,9 & 3 & 5,8 & 25 & 48,1 & 17 & 32,7 \\
\hline $\begin{array}{l}\text { - Tanggung jawab pada kesehatan } \\
\text { ada pada diri sendiri }\end{array}$ & - & - & 4 & 7,7 & 2 & 3,8 & 8 & 15,4 & 25 & 48,1 & 13 & 25,0 \\
\hline $\begin{array}{l}\text { - } \quad \text { Kondisi kesehatan yang tidak } \\
\text { baik disebabkan oleh diri sendiri }\end{array}$ & - & - & 4 & 7,7 & 4 & 7,7 & 16 & 30,8 & 26 & 50,0 & 2 & 3,8 \\
\hline $\begin{array}{l}\text { - Hal yang dilakukan diri sendiri } \\
\text { akan mempengaruhi kondisi } \\
\text { kesehatan }\end{array}$ & - & - & 1 & 1,9 & 1 & 1,9 & 3 & 5,8 & 35 & 67,3 & 12 & 23,1 \\
\hline $\begin{array}{l}\text { - Jika kondisi membaik layak } \\
\text { mendapat penghargaan, jika }\end{array}$ & 8 & 15,4 & 11 & 21,2 & 6 & 11,5 & 11 & 21,2 & 12 & 23,1 & 4 & 7,7 \\
\hline $\begin{array}{l}\text { kondisi memburuk patut } \\
\text { disalahkan }\end{array}$ & 1 & 1,9 & 3 & 5,8 & 3 & 5,8 & 13 & 25,0 & 25 & 48,1 & 7 & 13,5 \\
\hline
\end{tabular}

- Kondisi memburuk karena belum bisa menjaga diri

Powerful-others health locus of control

- Konsultasi ke tenaga kesehatan setiap kali kondisi memburuk

Menemui dokter secara teratur akan mengatasi masalah kesehatan

- Orang lain berperan besar dalam kondisi kesehatan

- Pandangan orang lain mempengaruhi kondisi kesehatan

- Mengikuti arahan dokter adalah cara menjaga kondisi kesehatan Bantuan dari orang lain mempengaruhi kondisi kesehatan

Chance Locus of Control

- Pasrah atas kondisi kesehatan sendiri

- $\quad$ Kondisi kesehatan dipengaruhi hal-hal yang bersifat kebetulan Keberuntungan mempengaruhi kondisi kesehatan

- Nasib baik mempengaruhi kondisi kesehatan

- Kondisi kesehatan memburuk merupakan nasib Pandangan orang lain mempengaruhi kondisi kesehatan

\begin{tabular}{|c|c|c|c|c|c|c|c|c|c|c|c|}
\hline 2 & 3,8 & 3 & 5,8 & 3 & 5,8 & 2 & 3,8 & 23 & 44,2 & 19 & 36,5 \\
\hline- & - & 1 & 1,9 & - & - & 2 & 3,8 & 22 & 42,3 & 27 & 51,9 \\
\hline 3 & 5,8 & 11 & 21,2 & 7 & 13,5 & 9 & 17,3 & 14 & 26,9 & 8 & 15,4 \\
\hline 13 & 25 & 19 & 36,5 & 11 & 21,2 & 4 & 7,7 & 5 & 9,6 & - & - \\
\hline- & - & 1 & 1,9 & - & - & 6 & 11,5 & 20 & 38,5 & 25 & 48,1 \\
\hline 3 & 5,8 & 8 & 15,4 & 6 & 11,5 & 17 & 32,7 & 12 & 23,1 & 6 & 11,5 \\
\hline 12 & 23,1 & 25 & 48,1 & 7 & 13,5 & 1 & 1,9 & 6 & 11,5 & 1 & 1,9 \\
\hline 7 & 13,5 & 21 & 40,4 & 11 & 21,2 & 8 & 15,4 & 5 & 9,6 & - & - \\
\hline 3 & 5,8 & 12 & 23,1 & 10 & 19,2 & 12 & 23,1 & 14 & 26,9 & 1 & 1,9 \\
\hline 9 & 17,3 & 12 & 23,1 & 12 & 23,1 & 10 & 19,2 & 7 & 13,5 & 2 & 3,8 \\
\hline 11 & 21,2 & 9 & 17,3 & 10 & 19,2 & 4 & 7,7 & 16 & 30,8 & 2 & 3,8 \\
\hline 4 & 7,7 & 9 & 17,3 & 5 & 9,6 & 12 & 23,1 & 15 & 28,8 & 7 & 13,5 \\
\hline
\end{tabular}

Ket : STS (Sangat Tidak Setuju), TS (Tidak Setuju), ATS (Agak Tidak Setuju), AS (Agak Setuju), S (Setuju), SS (Sangat Setuju) 
Tabel 4 Deskripsi Nilai Dimensi Health Locus of Control Responden pada Pasien DM Tipe 2 di RSUD

Kota Depok Tahun 2020

\begin{tabular}{cccc}
\hline Dimensi & Mean* & Minimal* & Maksimal* \\
\hline Internal HLOC & 74,89 & 55,56 & 94,44 \\
Powerful-others & 71,47 & 38,89 & 94,44 \\
HLOC & & & \\
Chance LOC & 51,70 & 22,22 & 83,33 \\
\hline
\end{tabular}

(*) Ket: Nilai dalam skala 100

Tabel 5. Distribusi Responden Berdasarkan Karakteristik Pasien DM Tipe 2 Di RSUD Kota Depok Tahun 2020

\begin{tabular}{lcc}
\hline \multicolumn{1}{c}{ Kategori } & f & \% \\
\hline Usia & & \\
Non Risti $(<45$ tahun $)$ & 6 & 11,5 \\
Risti $(\geq 45$ tahun $)$ & 46 & 88,5 \\
Total & $\mathbf{5 2}$ & $\mathbf{1 0 0}$ \\
Jenis Kelamin & $\mathrm{f}$ & $\%$ \\
Pria & 17 & 32,7 \\
Wanita & 35 & 67,3 \\
Total & $\mathbf{5 2}$ & $\mathbf{1 0 0}$ \\
Tingkat Pendidikan & $\mathrm{f}$ & $\%$ \\
Rendah & 28 & 53,8 \\
Tinggi & 24 & 46,2 \\
Total & $\mathbf{5 2}$ & $\mathbf{1 0 0}$ \\
Pekerjaan & $\mathrm{f}$ & $\%$ \\
Bekerja & 6 & 11,5 \\
Tidak Bekerja & 46 & 88,5 \\
Total & $\mathbf{5 2}$ & $\mathbf{1 0 0}$ \\
Lama Menderita DM & $\mathrm{f}$ & $\%$ \\
$>5$ tahun & 22 & 42,3 \\
$\leq 5$ tahun & 30 & 57,7 \\
Total & $\mathbf{5 2}$ & $\mathbf{1 0 0}$ \\
\hline
\end{tabular}

Tabel 4 menunjukkan rata-rata nilai internal health locus of control responden adalah 74,89 dengan nilai yang paling rendah adalah 55,56 dan yang paling tinggi adalah 94,44. Nilai rata-rata powerful-others health locus of control responden adalah 71,47 dengan nilai paling rendah adalah 38,89 dan yang paling tinggi 94,44 . Nilai rata-rata chance locus of control responden adalah 51,70 (skala 100) dengan nilai yang paling rendah adalah 22,22 dan yang paling tinggi 83,33.
Tabel 5 menunjukkan bahwa $88,5 \%$ responden berusia berisiko tinggi (risti) sedangkan untuk responden yang berusia nonrisiko tinggi (non risti) hanya sebesar $11,5 \%$. Terdapat $67,3 \%$ responden berjenis kelamin wanita sedangkan untuk responden yang berjenis kelamin pria hanya sebesar $32,7 \%$. Terdapat 53,8\% responden memiliki tingkat pendidikan rendah sedangkan untuk responden yang memiliki tingkat pendidikan tinggi hanya sebesar 46,2\%. 88,5\% responden tidak bekerja sedangkan untuk responden yang bekerja hanya sebesar $11,5 \% .57,7 \%$ responden menderita DM tipe $2 \leq 5$ tahun sedangkan untuk responden yang menderita DM tipe $2>$ 5 tahun hanya sebesar $42,3 \%$.

Tabel 6 dan 7 menunjukkan distribusi jawaban pengetahuan DM, dimana responden rata-rata menjawab bahwa pada penderita DM yang tidak diobati akan terjadi peningkatan gula darah $(96,2 \%)$ dan diabetes dapat merusak ginjal $(84,6 \%)$. Selain itu rata-rata responden juga menjawab bahwa DM disebabkan karena pola makan salah $(80,8 \%)$, pengelolaan DM dilakukan melalui diet $(73,1 \%)$ dan tujuan dari diet adalah untuk mencapai kadar gula normal $(86,5 \%)$.

Tabel 8 menunjukkan rata-rata nilai pengetahuan DM responden adalah 59,10 dengan nilai yang paling rendah adalah 26,67 dan yang paling tinggi adalah 100 . Sedangkan, tabel 9 menunjukkan bahwa pada Health Locus of Control (HLOC) dimensi internal HLOC dan powerful-others HLOC menunjukkan keeratan hubungan sedang dan positif $(0,46$ dan 0,28$)$ sedangkan chance locus of control menunjukkan keeratan hubungan sedang dan negatif terhadap kepatuhan diet ($0,28)$.

Tabel 6. Distribusi Responden Menurut Butir-Butir Pengetahuan DM pada Pasien DM Tipe 2 di RSUD Kota Depok Tahun 2020

\begin{tabular}{llccccc}
\hline \multirow{2}{*}{ Butir-Butir Pengetahuan DM } & \multicolumn{2}{c}{ Ya } & \multicolumn{2}{c}{ Tidak } & \multicolumn{2}{c}{ Tidak tahu } \\
& f & \% & f & \% & f & \% \\
\hline$-\quad \begin{array}{l}\text { Penyakit diabetes mellitus dapat } \\
\text { disembuhkan }\end{array}$ & 19 & 36,5 & 20 & 38,5 & 13 & 25,0 \\
$-\quad \begin{array}{l}\text { Penyakit diabetes yang tidak dio- } \\
\text { bati menyebabkan peningkatan } \\
\text { kadar gula darah }\end{array}$ & 50 & 96,2 & 1 & 1,9 & 1 & 1,9 \\
- & & & & & & \\
$\quad \begin{array}{l}\text { Penyakit diabetes mellitus } \\
\text { berisiko merusak ginjal }\end{array}$ & 44 & 84,6 & 1 & 1,9 & 7 & 13,5 \\
\hline
\end{tabular}


Tabel 7. Lanjutan Distribusi Responden Menurut Butir-Butir Pengetahuan DM pada Pasien DM Tipe 2 di RSUD Kota Depok Tahun 2020

\begin{tabular}{|c|c|c|}
\hline Butir-Butir Pengetahuan DM & f & $\%$ \\
\hline \multicolumn{3}{|l|}{ Penyebab Penyakit DM } \\
\hline - Keturunan & 39 & 75,0 \\
\hline - Kegemukan & 19 & 36,5 \\
\hline - $\quad$ Pola makan salah & 42 & 80,8 \\
\hline - $\quad$ Kelainan insulin & 6 & 11,5 \\
\hline - $\quad$ Tidak tahu & 5 & 9,6 \\
\hline \multicolumn{3}{|l|}{ Pengelolaan Penyakit DM } \\
\hline - $\quad$ Minum Obat/suntik insulin & 37 & 71,2 \\
\hline - Diet & 38 & 73,1 \\
\hline - Penyuluhan & 11 & 21,2 \\
\hline - Olahraga & 37 & 71,2 \\
\hline - Tidak tahu & 4 & 7,7 \\
\hline \multicolumn{3}{|l|}{ Tujuan dari diet } \\
\hline - Mencapai kadar gula normal & 45 & 86,5 \\
\hline - $\quad$ Mencapai berat badan normal & 19 & 36,5 \\
\hline - $\quad$ Terhindar komplikasi & 38 & 73,1 \\
\hline - Dapat beraktivitas & 12 & 23,1 \\
\hline - $\quad$ Tidak tahu & 1 & 1,9 \\
\hline
\end{tabular}

Tabel 8. Deskripsi Nilai Pengetahuan DM Responden pada Pasien DM Tipe 2 di RSUD Kota Depok Tahun 2020

\begin{tabular}{cc}
\hline Parameter & Nilai* \\
\hline Mean & 59,10 \\
Minimal & 26,67 \\
Maksimal & 100
\end{tabular}

(*) Ket: Nilai dalam skala 100

Tabel 9. Hubungan Health Locus of Control dengan Kepatuhan Diet pada Pasien DM Tipe 2 di RSUD Kota Depok Tahun 2020

\begin{tabular}{ccc}
\hline \multicolumn{1}{c}{ Variabel } & Kepatuhan Diet (r) & p value \\
\hline Health Locus of Control & & \\
- Internal HLOC & 0,46 & 0,001 \\
- Powerful others HLOC & 0,28 & 0,041 \\
- Chance LOC & $-0,28$ & 0,045 \\
\hline
\end{tabular}

Tabel 10. Hubungan Usia, Jenis Kelamin, Tingkat Pendidikan, Pekerjaan dan Lama Menderita DM dengan Kepatuhan Diet pada Pasien DM Tipe 2 di RSUD Kota Depok Tahun 2020

\begin{tabular}{|c|c|c|c|c|c|}
\hline Variabel & $\mathbf{n}$ & Mean & SD & $T$ (t-test) & $p$ value \\
\hline \multicolumn{6}{|l|}{ Usia } \\
\hline Non risti & 6 & 72,83 & 13,18 & 1,645 & 0,106 \\
\hline Risti & 46 & 65,37 & 10,09 & & \\
\hline \multicolumn{6}{|l|}{ Jenis Kelamin } \\
\hline Pria & 17 & 61,65 & 11,39 & $-2,254$ & 0,029 \\
\hline Wanita & 35 & 68,46 & 9,61 & & \\
\hline \multicolumn{6}{|l|}{ Tingkat Pendidikan } \\
\hline Rendah & 28 & 66,20 & 10,91 & $-0,026$ & 0,979 \\
\hline Tinggi & 24 & 66,28 & 10,50 & & \\
\hline \multicolumn{6}{|l|}{ Pekerjaan } \\
\hline Bekerja & 6 & 61,11 & 14,90 & $-1,265$ & 0,212 \\
\hline Tidak bekerja & 46 & 66,90 & 9,95 & & \\
\hline \multicolumn{6}{|c|}{ Lama Menderita DM } \\
\hline$>5$ tahun & 22 & 66,91 & 11,75 & 0,392 & 0,697 \\
\hline$\leq 5$ tahun & 30 & 65,74 & 9,88 & & \\
\hline
\end{tabular}


Tabel 11. Hubungan Pengetahuan DM dengan Kepatuhan Diet pada Pasien DM Tipe 2 di RSUD Kota Depok Tahun 2020

\begin{tabular}{ccc} 
Variabel & Kepatuhan Diet $(\mathbf{r})$ & $\boldsymbol{p}$ value \\
\hline Pengetahuan DM & 0,11 & 0,441 \\
\hline
\end{tabular}

Tabel 10 menunjukkan bahwa terdapat perbedaan rata-rata yang signifikan kepatuhan diet antara jenis kelamin (pria dengan wanita) $(0,029<0,05)$ dimana wanita memiliki nilai rata-rata kepatuhan yang lebih baik dibandingkan pria $(68,46>61,65)$.

Tabel 11 menunjukkan bahwa variabel pengetahuan memiliki bentuk korelasi positif dan kekuatan hubungan rendah $(0,11)$.

\section{PEMBAHASAN}

Kepatuhan terhadap diet DM merupakan salah satu perawatan yang harus dilakukan oleh penderita DM Tipe 2. Dari hasil penelitian ini diketahui bahwa nilai rata-rata pada kepatuhan responden adalah 66,23 dari skala 100 dimana angka tersebut merepresentasikan bahwa kepatuhan responden dalam kategori cukup. Hasil penelitian juga menunjukkan bahwa nilai rata-rata pada dimensi internal dan powerful others adalah 74,89 dan 71,47 dari skala 100 dimana angka tersebut merepresentasikan bahwa lokus kendali responden tinggi. Di sisi lain, pada dimensi chance locus of control nilai rata-rata yang didapat adalah 51,70 (skala 100) yang merepresentasikan bahwa lokus kendali responden rendah.

Hasil pada penelitian ini menunjukkan bahwa terdapat korelasi positif antara dimensi health locus of control yaitu internal health locus of control (IHLOC) $(\mathrm{r}=0,46)$ dan powerful-others health locus of control (POHLOC) $(\mathrm{r}=0,28)$ dengan kepatuhan diet. Disisi lain, dimensi chance locus of control (CLOC) berkorelasi secara negatif kepatuhan diet $(\mathrm{r}=-0,28)$. Penelitian ini menunjukkan terdapat hubungan antara health locus of control pada setiap dimensinya dengan kepatuhan diet dimana hasil penelitian ini sejalan dengan Zahednezhad et al. ${ }^{15}$, Abredari et al. ${ }^{16}$ dan Umasugi et al. ${ }^{17}$ namun hasil penelitian ini tidak sejalan dengan penelitian Pourhoseinzadeh et al. ${ }^{18}$.

Pada variabel usia menunjukkan bahwa sebagian besar responden berusia risiko tinggi atau risti ( $\geq 45$ tahun) (88,5\%). Dalam hasil penelitian ini menyatakan bahwa tidak terdapat perbedaan yang signifikan antara kepatuhan pada usia risti dengan usia non risti $(0,106>0,05)$. Artinya, tidak ada hubungan yang signifikan antara usia dengan kepatuhan diet. Hasil penelitian ini sejalan dengan penelitian yang dilakukan oleh Yulia ${ }^{19}$ dan Haque $^{20}$ namun tidak sejalan dengan penelitian yang dilakukan oleh Hestiana ${ }^{21}$. Menurut Parajuli et al. ${ }^{6}$ seiring dengan bertambahnya usia seseorang maka kepatuhannya akan semakin menurun yang disebabkan penurunan fungsi kognitif. Menurut penelitian Alhariri et al. ${ }^{22}$, kepatuhan diet responden cenderung baik pada pasien yang berusia diantara 40-60 tahun dibandingkan dengan pasien $<40$ tahun.

Pada variabel jenis kelamin sebagian besar pasien DM tipe 2 adalah responden wanita $(67,3 \%)$ dan berdasarkan analisis menunjukkan bahwa ada perbedaan yang signifikan antara kepatuhan pria dan wanita $(0,029<0,05)$. Artinya, terdapat hubungan yang signifikan antara jenis kelamin dengan kepatuhan, dimana responden wanita jauh lebih patuh dibandingkan responden pria $(68,46>61,65)$. Hasil penelitian ini sejalan dengan penelitian yang dilakukan oleh Kavitha et al. $^{23}$ namun tidak sejalan dengan hasil penelitian yang dilakukan oleh Lestari ${ }^{14}$. Rendahnya tingkat kepatuhan pada pria dapat disebabkan karena perbedaan gaya hidup. ${ }^{23}$ Berdasarkan uji stratifikasi didapatkan hasil bahwa terdapat hubungan antara health locus of control dimensi internal dengan kepatuhan diet dan tidak ada hubungan antara health locus of control dimensi powerful-others dan chance dengan kepatuhan diet baik pada pria dan wanita. Oleh karena itu diduga bahwa jenis kelamin memiliki peran sebagai variabel pengganggu untuk hubungan health locus of control dimensi internal dengan kepatuhan diet.

Pada variabel tingkat pendidikan sebagian besar responden memiliki tingkat pendidikan rendah $(53,8 \%)$ Dalam hasil penelitian ini menunjukkan bahwa tidak ada perbedaan yang signifikan antara tingkat pendidikan dengan kepatuhan diet $(0,979>0,05)$. Artinya, tidak ada hubungan yang signifikan antara tingkat pendidikan dengan kepatuhan diet. Penelitian ini sejalan dengan penelitian yang dilakukan oleh Haque $^{20}$ namun tidak sejalan dengan penelitian Hontong et al. ${ }^{24}$ Menurut beberapa 
penelitian, seseorang yang memiliki tingkat pendidikan tinggi sering dikaitkan dengan kesadaran dan kewaspadaan yang lebih baik terhadap komplikasi penyakit diabetes dan lebih patuh terhadap diet dibandingkan dengan yang memiliki tingkat pendidikan rendah. ${ }^{25}$ Meski demikian, pendidikan tidak selalu menjadi indikator yang dapat menentukan perilaku kesehatan karena perilaku seseorang tidak hanya terbentuk saat melaksanakan pendidikan namun bisa terbentuk akibat adanya pengaruh dari lingkungan di sekitarnya.

Pada distribusi pekerjaan responden sebagian besar adalah responden yang tidak bekerja $(88,5 \%)$ Hasil penelitian ini menunjukkan bahwa tidak ada perbedaan yang signifikan antara pekerjaan dengan kepatuhan diet $(0,212>0,05)$. Artinya, tidak ada hubungan yang signifikan antara pekerjaan dengan kepatuhan diet. Hasil ini sejalan dengan penelitian yang dilakukan oleh Haque. ${ }^{20}$ Hasil ini tidak sejalan dengan penelitian yang dilakukan oleh Alhariri et al. ${ }^{22}$, dimana menurut penelitiannnya seseorang yang bekerja cenderung lebih patuh terhadap diet dibandingkan yang tidak bekerja. Namun, beberapa pendapat mengatakan bahwa seseorang yang bekerja cenderung merasakan stress yang akan mempengaruhi perilaku makannya. Kecenderungan ini membuat orang yang bekerja lebih memilih memakan makanan yang tidak sehat untuk dikonsumsi. ${ }^{26}$

Proporsi responden pada variabel lama menderita DM menunjukkan sebagian besar pasien menderita $\mathrm{DM} \leq 5$ tahun $(57,7 \%)$. Hasil analisis menunjukkan bahwa tidak terdapat perbedaan yang signifikan antara lama menderita DM dengan kepatuhan diet $(0,697>0,05)$. Artinya, tidak ada hubungan yang signifikan antara lama menderita DM dengan kepatuhan diet. Penelitian ini sejalan dengan hasil penelitian yang dilakukan oleh Elsous et al. ${ }^{27}$ namun tidak sejalan dengan penelitian yang dilakukan oleh Yulia ${ }^{19}$ yang menunjukkan bahwa terdapat hubungan antara lama menderita DM dengan kepatuhan diet. Yulia ${ }^{19}$ menyatakan bahwa semakin lama menderita DM maka kecenderungan untuk mengkonsumsi makan-makanan yang tidak sehat, tidak mengikuti program diet dan kebosanan akan meningkat.
Pengetahuan merupakan kemampuan yang dinilai penting untuk dimiliki pasien agar dapat mengurangi dampak yang disebabkan oleh penyakit $\mathrm{DM}^{28}$ Dalam penelitian ini pengetahuan responden memiliki nilai ratarata sebesar 59,10 dari skala 100 yang artinya pengetahuan responden terhadap DM dalam kategori cukup. Hasil penelitian ini menunjukkan bahwa tidak ada hubungan yang signifikan antara pengetahuan dengan kepatuhan diet $(0,441>0,05)$. Hasil penelitian ini sejalan dengan penelitian yang dilakukan oleh Dewi et al. ${ }^{29}$ dan Han et al. ${ }^{30}$ namun penelitian ini tidak sejalan dengan Nurhidayat. ${ }^{31}$ Pengetahuan merupakan salah satu faktor yang penting untuk menjalankan pengobatan, seseorang yang melakukan suatu perilaku karena didasari oleh pengetahuan akan lebih mudah melaksanakan perilaku tersebut dibandingkan dengan yang tidak memiliki pengetahuan yang cukup. $^{29}$ Namun tingkat pengetahuan bisa dipengaruhi oleh status sosial ekonomi seseorang, semakin baik status ekonominya maka pengetahuannya akan semakin baik. ${ }^{30}$

\section{KESIMPULAN}

Hasil penelitian yang dilakukan pada pasien DM tipe 2 di RSUD Kota Depok tahun 2020 menunjukkan bahwa terdapat hubungan yang signifikan antara health locus of control dimensi internal, powerful others dan chance dengan kepatuhan diet dengan kekuatan hubungan sedang dan arah korelasi positif pada dimensi internal dan powerful others dan negatif pada dimensi chance. Untuk faktor lain yang berhubungan dengan kepatuhan diet seperti usia, tingkat pendidikan, pekerjaan, lama menderita DM dan pengetahuan tidak menunjukkan hubungan yang signifikan dengan kepatuhan diet. Namun jenis kelamin menunjukkan hubungan yang signifikan dengan kepatuhan diet dimana wanita memiliki kepatuhan yang lebih baik dibandingkan pria $(68,46>61,65)$ sehingga variabel jenis kelamin dianggap sebagai variabel pengganggu antara hubungan health locus of control terhadap kepatuhan diet.

\section{SARAN}

Bagi pihak RSUD Kota Depok dapat melakukan kegiatan penyuluhan untuk 
meningkatkan kesadaran dan tanggung jawab pasien terhadap pentingnya melakukan penatalaksanaan DM khususnya terhadap pasien pria dikarenakan pasien pria cenderung tidak patuh, melalui pemberian edukasi terkait DM dengan menggunakan bahasa yang lebih awam. Bagi tenaga kesehatan di RSUD Kota Depok agar dapat memberikan panduan dan arahan agar pasien dapat bertanggungjawab dalam kepatuhan diet. Selain itu para tenaga kesehatan dapat melakukan kontrol terhadap perkembangan pasien dalam menjalankan kepatuhan diet dan melibatkan pasien dalam membuat keputusan klinis. Memberikan sosialisasi kepada keluarga pasien DM tipe 2 agar keluarga dapat memberikan dukungan terhadap pasien juga diperlukan. Pihak RSUD Kota Depok diharapkan dapat membuat lembar self-assesment control untuk pasien DM tipe 2 yang dipergunakan agar pasien dapat mengevaluasi diet harian atau mingguan. Lembar ini diberikan agar pasien dapat menilai sendiri bagaimana kepatuhannya terhadap pelaksanaan diet.

\section{UCAPAN TERIMA KASIH}

Peneliti mengucapkan terima kasih kepada semua pihak yang telah membantu dalam proses pelaksanaan penelitian serta semua responden yang telah berpartisipasi dalam penelitian ini.

\section{DAFTAR REFERENSI}

1. WHO. Noncommunicable Diseases [Internet]. 2018 [cited 2020 Feb 10]. Available from: https://www.who.int/news-room/factsheets/detail/noncommunicablediseases

2. IDF. Diabetes Facts \& Figures [Internet]. 2020 [cited 2020 Feb 15]. Available from: https://www.idf.org/aboutdiabetes/what -is-diabetes/facts-figures.html

3. Kementerian Kesehatan RI. Situasi Dan Analisis Diabetes [Internet]. 2014. Available from: https://pusdatin.kemkes.go.id/resources /download/pusdatin/infodatin/infodatin -diabetes.pdf

4. Dinas Kesehatan Kota Depok. Profil
Kesehatan Kota Depok Tahun 2018 [Internet]. 2019. Available from: http://dinkes.depok.go.id/wpcontent/uploads/PROFILKESEHATAN-KOTA-DEPOKTAHUN-2018.pdf

5. WHO. Adherence To Long-Term Therapies: Evidence For Action [Internet]. 2003. Available from: https://www.who.int/chp/knowledge/pu blications/adherence_full_report.pdf

6. Parajuli J, Saleh F, Thapa N, Ali L. Factors Associated With Nonadherence To Diet And Physical Activity Among Nepalese Type 2 Diabetes Patients; A Cross Sectional Study. BMC Res Notes. 2014;7(1):1-9.

7. Sarafino EP, Smith TW. Health Psychology: Biopsychosocial Interactions 7th Edition. John Wiley \& Sons, Incorporated; 2011.

8. Sangeeta, Shobhana, Rana SS. Health Locus Of Control As Correlate Of Health Promoting Behaviors. Indian J Heal Wellbeing. 2015;6(6):580-4.

9. Kassianos AP, Symeou M, Ioannou M. The Health Locus Of Control Concept : Factorial Structure, Psychometric Properties And Form Equivalence Of The Multidimensional Health Locus Of Control Scales. Heal Psychol Open. 2016;1-10.

10. Susanti RD. Hubungan Motivasi Dan Health Locus Of Control Dengan Kepatuhan Diet Pada Penderita Diabetes Mellitus. Universitas Airlangga; 2018.

11. Minhas MT. Interaction Of Physical Activity, Diet, Health Locus Of Control And Quality Of Life Among Finnish University Students. University of Jyvaskyla; 2013.

12. Hidayati A. Hubungan Health Locus of Control Dengan Mekanisme Koping Pada Pasien Diabetes Mellitus Tipe 2 Di Wilayah Kerja Puskesmas Patrang Kabupaten Jember. Universitas jember; 2017.

13. Gultom YT. Tingkat pengetahuan Pasien Diabetes Mellitus Tentang Manajemen Diabetes Mellitus Di Rumah Sakit Pusat Angkatan Darat 
Gatot Soebroto Jakarta Pusat. Fakultas Ilmu Keperawatan Universitas Indonesia. Universitas Indonesia; 2012.

14. Lestari TS. Hubungan Psikososial Dan Penyuluhan Gizi Dengan Kepatuhan Diet Pasien Diabetes Melitus Tipe 2 Rawat Jalan Di RSUP Fatmawati Tahun 2012. Fakultas Kesehatan Masyarakat Universitas Indonesia. 2012.

15. Zahednezhad $\mathrm{H}$, Poursharifi $\mathrm{H}$, Babapour J. Memory, Health Locus of Control and Adherence in Type II Diabetic patients in Iran - Tabriz. Procedia - Soc Behav Sci. 2011;30:2621-4.

16. Abredari H, Bolourchifard F, Rassouli M, Nasiri N, Taher M, Abedi A. Health Locus of Control and Self-Care Behaviors in Diabetic Foot Patients. Med J Islam Repub Iran. 2015;29:283.

17. Umasugi MT, Tunny IS, Tappang Y, Asni U. The Relation Between Health Locus Of Control And Compliance Of Diet Management Type II Of Diabetes Mellitus In Piru Hospital, Western Part Of Seram Regency 2016. Dama Int J Res. 2016;1(11):74-9.

18. Pourhoseinzadeh M, Gheibizadeh M, Moradikalboland M, Cheraghian B. The Relationship between Health Locus of Control and Health Behaviors in Emergency Medicine Personnel. IJCBNM . 2017;5(4).

19. Yulia S. Kepatuhan Dalam Menjalankan Diet Pada Penderita Diabetes Mellitus Tipe 2 (Studi Kasus di Puskesmas Kedungmundu Tahun 2015). Fakultas Ilmu Keolahragaan Universitas Negeri Semarang. Universitas Negeri Semarang; 2015.

20. Haque DF. Hubungan Antara Pelayanan Kesehatan Dan Faktor Lainnya Dengan Kepatuhan Diet Pada Anggota PERSADIA Penyandang DM Tipe 2 Di Depok. Universitas Indonesia; 2013.

21. Hestiana DW. Faktor-faktor Yang Berhubungan Dengan Kepatuhan Dalam Pengelolaan Diet Pada Pasien Rawat Jalan Diabetes Mellitus Tipe 2 Di Kota Semarang. J Heal Educ. 2017;2(2):138-45.

22. Alhariri A, Daud F, Almaiman A,
Saghir S ayesh M. Factors Associated With Adherence To Diet And Exercise Among Type 2 Diabetes Patients In Hodeidah City , Yemen. Diabetes Manag. 2017;7(3):264-71.

23. Kavitha S, Nalini G., Suresh R., Deepak P, Jayashree V, Nagaral V. Treatment Adherence and Factors Contributing to Non Adherence Among Type 2 Diabetes Mellitus Patients in A Tertiary Care Hospital: A Cross Sectional Study. Int J Basic Clin Pharmacol. 2017;6(3):689-94.

24. Hontong N, Kaunang WP., Ratag BT. Hubungan antara Tingkat Pendidikan, Pengetahuan, dan Dukungan Keluarga dengan kepatuhan Diet Pasien Diabetes Mellitus di RSU Pancaran Kasih GMIM Manado. Fak Kesehat Masy Univ Sam ratulangi. 2016;

25. Al-rasheedi AAS. The Role of Educational Level in Glycemic Control among Patients with Type II Diabetes Mellitus. Int J Health Sci (Qassim). 2014;8(2).

26. Tanaka R, Tsuji M, Asakura K, Senju A, Shibata E, Kusuhara K, et al. Variation in Men's Dietary Intake Between Occupations, Based on Data From the Japan Environment and Children's Study. Am J Mens Health. 2018;12(5):1621-34.

27. Elsous A, Radwan M, Al-Sharif H, Abu Mustafa A. Medications Adherence and Associated Factors among Patients with Type 2 Diabetes Mellitus in the Gaza Strip, Palestine. Front Endocrinol (Lausanne) [Internet]. 2017 [cited 2020 Jul 8];8. Available from: www.frontiersin.org

28. Kusnanto, Sundari PM, Asmoro CP, Arifin H. Penurunan Tingkat Stres Penderita Diabetes Mellitus Yang Menjalani Diet Melalui Diabetes SelfManagement. 2018; Available from: http://repository.unair.ac.id/85989/5/P ENURUNAN TINGKAT STRES PENDERITA DIABETES MELLITUS.pdf

29. Dewi T, Amir A, Gizi J, Kemenkes PK, D-iv AP, Gizi J, et al. Kepatuhan Diet pasien DM Berdasarkan Tingkat 
Pengetahuan dan Dukungan Keluarga di Wilayah Puskesmas Sudiang raya. 2018;25:55-63.

30. Han CY, Geok C, Chan B, Lim SL, Zheng X, Woon ZW, et al. DiabetesRelated Nutrition Knowledge and Dietary Adherence in Patients with Type 2 Diabetes Mellitus: A MixedMethods Exploratory Study. Proc Singapore Healthc. 2020;29(2):81-90.

31. Nurhidayat I. Faktor-Faktor Yang Berhubungan Dengan Kepatuhan Penatalaksanaan Diet Pada Pasien Diabetes Mellitus. Fakultas Kedokteran dan Ilmu Kesehatan Universitas Muhammadiyah Yogyakarta. 2017. 